Jurnal Pendidikan Bahasa dan Sastra Indonesia is licensed under

A Creative Commons Attribution-Non Commercial 4.0 International License

\title{
Wacana Percakapan Mappitu Etnis Bugis Wajo Sulawesi Selatan, Indonesia Pendekatan Etnografi Komunikasi
}

\author{
Juanda $^{1)}$, Azis $^{2)}$ \\ 1. Program Studi Bahasa dan Sastra Indonesia, FBS,Universitas Negeri Makassar \\ E-mail: juanda@unm.ac.id \\ 2. Program Studi Pendidikan Bahasa dan Sastra Indonesia, FBS,Universitas Negeri Makassar \\ E-mail:azis@unm.ac.id
}

\begin{abstract}
Abstrak. Penelitian ini dilatar belakangi oleh tergerusnya budaya lokal. Mappitu sebagai proses mengundang tamu kehormatan tujuh hari sebelum acara pernikahan dilaksanakan sebagai salah satu rangkaian prosesi pernikahan pada suku Bugis. Tujuan penelitian ini menganalisis bentuk dan isi percakapan mappitu etnis Bugis. Penelitian ini merupakan jenis penelitian kualitatif deskriptif. Sumber data diambil dari dialog lisan tuturan masyarakat Bugis di Kabupaten Wajo, Sulawesi Selatan. Data dikumpulkan dengan menggunakan metode observasi partisipan. Pengambilan data dengan teknik perekaman. Selanjutnya data dianalisis berdasarkan pendekatan etnografi komunikasi. Hasil penelitian menunjukkan bentuk tuturan dalam undangan mappitu berbentuk frosen. Pada undangan pihak yang mengundang saja yang menggunakan bahasa genre undangan mappitu, frozen dengan menggunakan pakaian adat. Pihak yang diundang menggunakan percakapan sehari-hari. Genre mappitu adalah dialog lisan. Undangan mappitu dalam penelitian ini mencapai hasil yang diharapkan karena tamu kehormatan yang diundang secara mappitu menghadiri pesta pernikahan. Mappitu memiliki unsur: Setting: bola arung 'rumah bangsawan' partisipan tujuh orang berpakaian adat dan seorang tuan rumah, ends: mengudang, act: mappacci, akad nikah, dan maparola, key: formal, norma: sipakatau, dan genre: mappitu.
\end{abstract}

Kata Kunci: etnografi; analisis percakapan; Bugis.

\section{PENDAHULUAN}

Tuturan antara orang yang satu dengan orang yang lain atau kelompok yang satu dengan kelompok lainnya harus memperhatikan faktor kumunikatif dalam pertuturan tersebut. Setiap tuturan memiliki tujuan komunikatif. Pemahaman berbagai aspek komunikatif harus dilengkapi dengan pemahaman budaya tempat tuturan tersebut berlangsung. Biasa kita menemukan kesalahpahaman antara partisipan dalam berkomunikasi. Hal ini terjadi karena partisipan tidak mengerti aspek budaya yang menyertai pertuturan tempat terjadinya percakapan. Orang terdidik diharapkan menghargai perbedaan antara etnis serta terbuka terhadap pluralitas budaya (Juanda, 2010: 8).

Setiap etnis memiliki cara khas berkomunikasi. Penutur diharapkan mampu melihat konteks dan memilih tuturan yang serasi agar tidak melanggar tata norma percakapan. Di Bugis yang menggunakan bahasa Indonesia dan bahasa Bugis, bahasa Bugis dominan sebagai bahasa sehari-hari memiliki keunikan dalam pertuturan seperti mappitu. Mappitu memiliki nilai pendidikan harus dilestarikan karena ada nilai pundamental yaitu nilai sosial (Madyananda dan Umiyaryati, 2017:63). Hal ini dapat dilihat pada tuturan mappitu sebagai salah satu rangkaian dalam prosesi pernikahan. Mappitu merupakan rangkaian mengundang tamu menjelang tujuh hari sebelum kegiatan pernikahan. "mappitu", (serangkaian acara pernikahan), berkaitan erat dengan budaya tempat tuturan tersebut dilaksanakan.

Keunikan-keunikan pertuturan tersebut semestinya dipahami oleh etnis lainnya agar terjalin hubungan komuniksi yang baik antarpembicara atau pelaksanaan tuturan bersifat komunikatif. Pengkhususan di lingkungan etnis Bugis terutama pada generasi muda perlu mengetahui fenomena 
pertuturan tersebut agar kalau berbicara dapat dikatakan tahu adat atau tatakrama. Hubungan antara orang-orang atau etnis yang berkomunikasi merupakan aspek komunikatif yang perlu diperhatikan. Model tuturan ini dapat dikaji dengan berbagai pendekatan dalam wacana, antara lain pendekatan etnografi komunikasi. Telah banyak penelitian mengenai tuturan, percakapan antara lain: Yang (2007), Smith (2012), Kundharu (2013), Nevins (2013), Reyaz dan Priyanka Tripathi (2016), dan

Yang (2007), Namun, penelitian tersebut belum mengeksplorasi bentuk tuturan mappitu dalam etnis Bugis. Oleh karena itu, dalam penelitian ini peneliti memfokuskan pada bentuk dan isi percakapan mappitu etnis Bugis dan Tujuan menganalisis bentuk dan isi percakapan mappitu etnis Bugis.

Yang (2007) Dengan keadaan ini, dapat dilihat bahwa terdapat hubungan yang erat antara penggunaan bahasa dalam konteks dan norma-norma yang lugas, mapan dan sesuai dengan norma-norma yang berlaku dalam masyarakat. Dalam percakapan harus memperhatikan unsur paralinguistik, sociocentric seperti (Yang Wei, 2007:24) untuk ekspresi dengan pilihan tuturan 'but ah', 'you know?' Dalam penelitiannya, percakapan harus memperhatikan unsur paralinguistik, socio-centric seperti untuk ekspresi dengan pilihan tuturan 'but ah', 'you know?' realisasi giliran dam interaksi komunikasi. Retorika interupsi telah diuraikan (Smith, 2012). Afful (2017). pilihan pengaturan, hari, konteks situasi (adegan), pakaian peserta dan pengaturan kursi menyoroti sifat formal. Selanjutnya Reyaz, dan Priyanka Tripathi (2016) mengenai realisasi giliran dam interaksi komunikasi. Seseorang perlu memahami penggunaan bahasa dalam berkomunikasi, kajiannya bagaimana bertutur dari berbagai budaya dengan memperhatikan etnografi komunikasi. Bentuk, fungsi, penggunaan, dan karakteristik bahasa berdasarkan budaya, penggunaaan bahasa dalam benrtk wacana bagi etnis Jawa 'Friday Preaching' (Kundharu, 2013. Bentuk penggunaan bahasa pada seseorang, ethnography dialog (Nevins, 2013).

Etnografi komunikasi adalah sebuah pendekatan dalam analisis wacana yang didasarkan pada antropologi yang memusatkan perhatian pada penjelasan secara menyeluruh (holistik) makna, dan tingkah laku. Schiffrin (1994) telah mengemukakan bahwa pendekatan ini dalam analisis wacana berdasarkan pada kajian ilmu antropologi dan linguistik. Teori ini merupakan teori yang memerikan struktur tindak tutur. Menurut Hymes (1974), terdapat sejumlah tindak tutur seperti partisipan, konteks, pesan, cara, dan lain-lain. Teori ini digunakan sebagai acuan dasar untuk memerikan struktur konteks. Oleh karena itu, teori ini akan lebih diterangkan pada teori yang diterapkan. Teori etnografis mengamati bahwa bahasa, makna serta pemakaiannya, struktur tuturan atau genrenya serta pilihan-pilihan fungsi bahasa diatur norma-norma sosiokultural yang berjalan dan berlaku dalam kelompok etnis pemakai bahasa itu. Hymes (1974) memberikan sumbangan dalam bidang ini dengan memasukkan pandangan dari sosiologi dan antropologi yang berasal dari Malinowski; mencurahkan perhatian pada wacana sebagai realisasi budaya dalam bertindak dan menyatakan sikap serta kepada pembedaan fungsi referensi dan fungsi sosial bahasa. Seperti yang dinyatakan Hymes (1972) bahwa satu kalimat atau serangkaian kata dalam hubungan sintaksis yang sama, mungkin bisa berarti permintaan, perintah, pujian, hinaan, bergantung pada pemahaman yang ada di dalam msyarakat. Jadi, bentuk bukan merupakan indikator yang reliabel untuk kekuatan ilokusioner.

Bahasa yang menggunakan sistem norma dan aturan adalah bagian integral budaya. Bahasa yang digunakan dalam situasi komunikasi, peristiwa, dan tindakan sangat membantu mengenali norma budaya yang melatari tindak tanduk seseorang karena budaya itu diciptakan, dinegosiasi, dan didefinisikan secara terus-menerus dalam tindakan di antara orang-orang yang berpartisispasi di berbagai situasi interaktif. Hymes berpendapat bahwa teori lingustik harus memfokuskan pada penjelasan tentang kompetensi sebagai pengetahuan tentang kaidah-kaidah bahasa secara abstrak. Selanjutnya Hyme's (1972) memfokuskan pada kompetensi komunikatif (communicative commpetence). Kompetensi komunikatif yaitu penggunaan bahasa yang ditentukan oleh latar sosial, psikologis, budaya, dan pengetahuan tentang bahasa.

Dalam hal metodologi, Hyme's mengajukan suatu metode untuk menentukan peristiwa komunikasi. Keinformatifan menyangkut peristiwa yang disajikan diharapkan atau tidak diharapkan, diketahui atau tidak diketahui oleh pembicara atau pendengar (Juanda, 2011:19). Komponen-komponen komunikasi dirangkum dalam singkatan urutan huruf yang membentuk kata "SPEAKING." Ada 16 poin penting yang harus menjadi penekanan dalam model Hymes's SPEAKING seperti yang dikemukanan oleh Renkema (1993), yaitu setting, scene, speaker, addressor, hearer, addresse, purpose-outcomes, purpose-goals, form, content, keys, Channel, Form of speech, norm of interaction, norm of interpretation, and genres. Analisis komunikasi dapat dilakukan dengan menerapkan konsep-konsep unit-unit komunikasi tersebut sebagai taksonomi komunikasi seperti yang diuraikan di bawah ini. S: Setting : Waktu, tempat dan kondisi 
fisik yang lain, imbangan psikologis pada set setting dapat diganti, misalnya dari formal menjadi ketifak formalan.

P: Participants : Penutur atau pengirim atau pesapa mitra tutur, Pendengar atau pesapa

E: Ends : Maksud-keluaran,

Maksud-tujuan

A: Act $\quad$ : Bentuk dan isi pesan

K: Keys $\quad$ : Nada percakapan, serius atau santai

I: Instrument : Tulisan, lisan, telepon, HP, dialek, bahasa baku

$\mathrm{N}$ : Norm: Norma interaksi (interupsi),

Norma interpretasi

G: Genre : Cerita, iklan, dialog, dan sebagainya.

Schiffrin (1994) dalam beberapa karangan sejak tahun 1959 memberi sumbangan dalam bidang ini dan membawa pemikiran dari bidang sosiologi yang berasal dari Durkheim, yakni nosi fakta sosial. Ia membicarakan hal mengenai interaksi sosial termasuk pengunaan bahasa sebagai wahana tanda (sign-vechile) dalam wacana. Hubungan format fungsi dalam ujaran dihubungkan dengan aspek konteks tertentu. Analisis sistemik konteks antara format dan fungsi merupakan fitur penting dalam format etnografi.

Pada umumnya pendekatan etnografi memandang bahasa itu terutama tindak tutur sebagai penggunaan bahasa yang kontekstual yang memiliki makna di dalam tuturan itu sendiri untuk melayani fungsi-fungsi komunikasi yang sifatnya sosial. dalam perspektif penggunaan bahasa secara kontekstual, hanya dengan adanya konteks berupa situasi tempat bahasa itu digunakan baru data bahasa itu sesuai untuk dianalisis secara etnografis. Di dalam peran bahasa di dalam fungsi sosial bahasa itu berfungsi melayani kebutuhan penuturnya untuk mencapai tujuan-tujuan komunikasi. Tujuan-tujuan komunikasi tersebut menunjukkan bahasa itu bersifat problem solving, yaitu bahasa digunakan untuk memenuhi kebutuhan tertentu dan sifatnya sosial (Halliday, 1984) kebutuhan sosial tersebut merupakan makna yang mendasari tindak tutur itu. Ekspresi diungkapkan pada saat berinteraksi melalui percakapan (Garde, 2013:20).

\section{METODE}

Penelitian ini merupakan jenis penelitian kualitatif deskriptif. Analisis percakapan bersumber dari tradisi penelitian hermeneutik (Pasalo, 2015:14). Sumber data diambil dari dialog lisan tuturan masyarakat Bugis di Kabupaten Wajo, Sulawesi Selatan. Data dikumpulkan dengan menggunakan metode observasi partisipan.
Pengambilan data dengan teknik perekaman. Data tuturan lisan mappitu, penulis rekam pada saat terjadi percakapan dalam proses mengundang tamu kehormatan. Data rekaman tersebut ditranskripsikan. Selanjutnya data dianalisis berdasarkan setting, scene, speaker, addressor, hearer, addresse, purpose-outcomes, purpose-goals, form, content, keys, Channel, Form of speech, norm of interaction, norm of interpretation, and genres.

\section{HASIL DAN PEMBAHASAN}

Di bawah ini diuraikan beberapa analisis tuturan dalam bahasa Bugis.

Mappitu 'Undangan' Masyarakat Bugis pada daerah Wajo bilamana akan mengadakan pesta pernikahan maka ada acara mengundang tamu. Tamu yang diundang ada melalui undangan (tertulis) dan ada yang mendatangi rumah orang yang diundang secara langsung secara lisan yang disebut Mappitu. Hal ini dapat dilihat dari transkripsi rekaman berikut:

(1) A(a): "Assalamualaikum."

B(b): Waalaikum mussalam

B(c): "Pada Tudakki."

'Silakan duduk'

$\mathrm{A}(\mathrm{d})$ : "Iye."

'Ya'

(beberapa detik)

A(e):'Tabe taparajakka dampeng, taparajattoi dampeng Hamid mallaebine. Idimi iduppai tudang-tudang ri abottingenna Suardi, anaqna Hamid essona Ahad."

'Kami sebagai utusan menghaturkan mohon maaf dan permohonan maaf yang sebesarbesarnya dari Hamid dengan Istrinya. Kami mengundang tuan menghadiri acara pernikahan Suardi, anak Hamid pada hari Ahad.'

B(f): "Iye, narekko deggaga caui",

'Ya, kalau tidak ada halangan'

$\mathrm{B}(\mathrm{g})$ : "Appanna matanna"

'Kapan pestanya'

A(h): "Essona Ahad tanggala 19 uleng dua" 'Pada hari Ahad tanggal 19 Februari.'

B(i): "Topolepega balinna"

'Dari mana asal calon suaminya'

A(j): "Pole Bone"

'Dari kabupaten Bone'

$\mathrm{A}(\mathrm{k})$ : "Massimanna"

'Baiklah kami mohon diri

B(1): "Tassimangngi aleta"

'Silahkan'

Tuturan di atas dapat dibuatkan tabel seperti dibawah ini.

\begin{tabular}{|l|l|}
\hline \multicolumn{2}{|c|}{ Etnografi Komunikasi Mappitu } \\
\hline Setting & Bola Arung 'Rumah Bangsawan' \\
\hline
\end{tabular}




\begin{tabular}{|l|l|}
\hline \multirow{2}{*}{ Participants } & $\begin{array}{l}\text { Tujuh orang berpakaian adat (Baju Bodo } \\
\text { bagi perempuan dan Jas-Songko- } \\
\text { Pamiring bagi pria; satu orang tuan } \\
\text { rumah. }\end{array}$ \\
\hline Ends & Mengundang \\
\hline Act & $\begin{array}{l}\text { Menghadiri Acara pernikahan: } \\
\text { Mappacci, Akad Nikah, dan Mapparola. }\end{array}$ \\
\hline Key & Resmi atau Formal \\
\hline Norma & Interaksi Sipakatau \\
\hline Genre & Dialog Mappitu \\
\hline
\end{tabular}

Mappitu dalam etnis Bugis merupakan salah satu prosesi acara pernikahan berupa mengundang tamu kehormatan. Percakapan dalam prosesi tersebut dapat di uraikan seperti berikut ini. 1.Setting

Latar mengacu pada tempat (ruang space) dan waktu atau tempo (time) terjadinya percakapan. Peristiwa tutur (1) adalah dialog pada saat mengundang di rumah $\mathrm{Hj}$. Mase, salah satu rumah warga di Desa Awota, Kec. Keera, Kabupaten Wajo, Sulawesi Selatan pada sore hari setelah salat ashar. Scene atau setting pembicaraan di atas dapat berubah karena faktor psikologis yang mempengaruhi setting pembicaraan. Dapat di lihat berikut ini. A(a): Assalamualaikum hingga B(f): "Iye, narekko deggaga caui ." 'Ya, kalau tidak ada halangan' bersifat formal. Tiba-tiba berubah secara tidak formal pada percakapan $\quad \mathrm{B}(\mathrm{g})$ : "Appanna matanna." 'Kapan pestanya' hingga A(j): "Pole Bone." 'Dari kabupaten Bone' diakhiri kembali dengan suasana formal pada percakapan A(k): "Massimanna." 'Baiklah kami mohon diri B(l): "Tassimangngi aleta." 'Silakan'.

Jumlah orang yang datang mengundang adalah 7 orang; perempuan empat orang dan laki-laki tiga orang. Banyaknya orang yang datang mengundang sebagai simbol bahwa acara pernikahan lagi tujuh hari (ada juga tujuh orang, sebagai simbol bahwa acara pernikahan lagi tujuh hari). Rumah yang dikunjungi untuk diundang disesuaikan dengan kedudukan stratifikasi sosial masyarakat orang yang diundang tersebut. Orang yang diundang secara langsung dengan model seperti ini (mappitu) atau (makkasera) adalah kalangan atas (raja dan keluarganya). Kepala desa selalu menjadi perioritas. 2. Partisipan

Partisipan mengacu pada peserta percakapan, yakni pembicara (penyapa) dan pendengar atau kawan bicara (pesapa). A dan B di atas sebagai peserta percakapan. Atau peserta percakapan adalah tuan rumah satu orang dan utusan orang yang mengundang 'mappitu' tujuh orang. Pembicara dua orang. Satu orang utusan yang pengundang sebagai juru bicara dan tuan rumah sebagai pendengar atau orang yang diundang ditambah dengan pendengar dari orang yang mengundang sebanyak enam orang orang. Speaker adalah juru bicara yang mengundang; adressor adalah tuan rumah yang diundang, hearer adalah tuan rumah dan anggota utusan sebanyak enam orang. Peserta percakapan adalah pengundang enam orang ditambah juru bicara satu dan tuan rumah. Jadi, partisipan sebanyak delapan orang. Dalam percakapan digunakan kata idi, 'Anda' dalam konteks lain disebut deiksis persona seperti penelitian Azis dan Juanda (2018).

\section{Hasil}

Hasil mengacu pada hasil dan tujuan percakapan. Penyampaian undangan di atas berhasil dengan baik cara penyampaiannya. Hal ini dapat dilihat pada respons positif tuan rumah, B(f): Iye, narekko deggaga caui "Ya!, kalau tidak ada halangan"; $\mathrm{B}(\mathrm{g})$ : "Appanna matanna" 'kapan pestanya'. Namun, hasil 'purpose goals' pada saat itu belum bisa ditentukan. Nanti dikatakan berhasil bilamana tuan rumah yang diundang betul-betul menghadiri pesta perkawinan tersebut pada tanggal 19 Februari. Ternyata pada saat pesta perkawinan berlangsung, Ibu $\mathrm{Hj}$. Mase datang menghadiri pesta. Jadi, dalam hal ini undangan tersebut di atas berhasil dengan baik.

\section{Bentuk dan Isi Pesan}

Bentuk dan isi pesan atau amanat dapat berupa surat, esei, iklan, pemberitahuan, dan pengumuman. Bentuk dialog di atas berupa pemberitahuan atau undangan. Hal ini dapat dilihat pada A(e): "Tabe taparajakka dampeng, taparajattoi dampeng Hamid mallaebine. Idimi iduppai tudang-tudang ri abottingenna Suardi, anaqna Hamid essona Ahad." 'Kami sebagai utusan menghaturkan mohon maaf dan permohonan maaf yang sebesar-besarnya dari Hamid dengan Istrinya. Kami mengundang tuan menghadiri acara pernikahan Suardi, anak Hamid pada hari Minggu.' Jadi, isi tuturan ini adalah undangan menghadiri pesta pernikahan. Baik percakapan maupun dialog adalah jenis komunikasi dengan memprioriaskan penyampaian informasi (Wiratno, 2010: 119). Seseorang perlu memahami penggunaan bahasa dalam berkomunikasi (Reyaz, dan Priyanka Tripathi (2016: 9). Keserasian itulah yang diidentifikasi oleh Hymes (1974) sebagai kompetensi komunikatif. 5.Cara

Cara atau key mengacu pada semangat melaksanakan percakapan, misalnya bercakapcakap dengan penuh semangat menyala-nyala atau dengan cara santai, tenang dan meyakinkan. Penyampaian tuturan di atas adalah serius atau formal. kemampuan dan keterampilan yang memungkinkan pembicara untuk bertindak dan berinteraksi secara tepat dalam situasi komunikasi antarbudaya (Balboni and Fabio Caon, 2014: 1). Mempertahankan ciri khas kedaerahan dialek (Sandel, 2015: 2). ). Bentuk penggunaan bahasa pada seseorang, ethnography dialog (Nevins, 2013). 


\section{Sarana}

Sarana atau instrumentalitas mengacu pada bahasa yang digunakan yaitu penyampaian bentuk bahasa secara lisan. Bentuk tuturan 'form of speech' adalah bahasa standar' dalam hal ini bentuknya sudah tetap, penulis dapat mengatakan bentuk frozen' $\mathrm{A}(\mathrm{e})$ : "Tabe taparajakka dampeng, taparajattoi dampeng Hamid mallaebine. "Idimi iduppai tudang-tudang ri abottingenna Suardi, anaqna Hamid essona Ahad." 'Kami sebagai utusan menghaturkan mohon maaf dan permohonan maaf yang sebesar-besarnya dari Hamid dengan Istrinya. Kami mengundang Tuan menghadiri acara pernikahan Suardi, anak Hamid pada hari Ahad.'

Pola kalimat di atas selalu digunakan kepada siapa saja yang diundang secara lisan. Hanya yang diganti adalah nama orang tua yang akan mengadakan pesta dan nama si anak yang akan dinikahkan serta waktu penyelenggaraan pesta. Bentuk, fungsi, penggunaan, dan karakteristik bahasa berdasarkan budaya (Kundharu, 2013: 239). Bentuk tuturan di atas hanya digunakan pada acara mappitu, mengundang pada acara pernikhan secara lisan, formal, sesuai dengan budaya.

\section{Norma}

Norma mengacu pada perilaku peserta percakapan. Dalam percakapan di atas betul-betul tidak boleh diinterupsi. Pilihan pengaturan, hari, konteks situasi (adegan), pakaian peserta dan pengaturan kursi menyoroti sifat formal (Afful, 2017).

(1) A(a): "Assalamualaikum."

$\mathrm{B}(\mathrm{b})$ : Waalaikum mussalam

B(c): "Pada Tudakki."

'Silakan duduk'

$\mathrm{A}(\mathrm{d})$ : "Iye"

'Ya'

(beberapa detik)

A(e): "Tabe taparajakka dampeng, taparajattoi dampeng Hamid mallaebine. Idimi iduppai tudang-tudang ri abottingenna Suardi, anaqna Hamid essona Ahad."

'Kami sebagai utusan menghaturkan mohon maaf dan permohonan maaf yang sebesarbesarnya dari Hamid dengan Istrinya. Kami mengundang tuan menghadiri acara pernikahan Suardi, anak Hamid pada hari Minggu.'

B(f): "Iye, narekko deggaga caui."

'Ya, kalau tidak ada halangan'

$\mathrm{A}(\mathrm{a})$ hingga $\mathrm{B}(\mathrm{f})$ tidak ada interupsi karena bersifat formal nanti pada peralihan ke dalam bentuk tidak formal baru bisa di interupasi, yaitu pada $\mathrm{B}(\mathrm{g})$ : "Appanna matanna."

'Kapan pestanya'

A(h): "Essona Ahad tanggala seppulo arua uleng enneng.
Pada hari Minggu tanggal 19 Februari'

B(i): "Topolepega balinna."

'Dari mana asal calon suaminya'

$\mathrm{A}(\mathrm{j})$ : "Pole Bone."

'Dari kabupaten Bulumba'

8.Genre

Genre percakapan adalah undangan. Hal ini dapat dilihat pada bentuk Ahad yang digunakan bersifat frozen, yaitu pada

A(e): "Tabe taparajakka dampeng, taparajattoi dampeng Hamid mallaebine. Idimi iduppai tudang-tudang ri abottingenna Suardi, anaqna Hamid essona Ahad."

'Kami sebagai utusan menghaturkan mohon maaf dan permohonan maaf yang sebesarbesarnya dari Hamid dengan Istrinya. Kami mengundang Tuan menghadiri acara pernikahan Suardi, anak Hamid pada hari Minggu.'

Tidak ada interupsi dalam bentuk ini. Retorika interupsi diuraikan (Smith, 2012). Tidak ditemukan konjungsi, konjungsi digunakan menandai peristiwa yang menunjukkan bahwa ada hal yang perlu diperjelas agar tidak menimbulkan kalimat ambigu (Azis dan Juanda, 2017:89). Tuturan lebih mengutamakan kompetensi komunikatif dibandingkan komptensi gramatikal (Dowlatabadi and Leyli Jorfi, 2015).

\section{SIMPULAN DAN SARAN}

Tuturan undangan mappitu dimulai dengan ucapan-ucapan yang bersifat formal dan diakhiri dengan dialog-dialog yang bersifat nonformal. Pakaian partisipan pada undangan ada dua model yaitu orang yang mengundang tujuh orang menggunakan pakaian adat dan tuan rumah yang diundang tidak berpakaian adat. Bentuk tuturan dalam undangan mappitu berbentuk frosen. pada undangan pihak yang mengundang saja yang menggunakan bahasa genre undangan mappitu (frozen) pihak yang diundang menggunakan katakata yang biasa (percakapan sehari-hari). Dalam hal ini tentu memperhatikan tatakrama pembicaraan dalam bahasa Bugis, yaitu tidak boleh menginterupasi atau mendebat supaya dianggap sopan. Genre tuturan mappitu di atas bergenre dialog dan lisan. Pada undangan mappitu, hasil tidak kelihatan pada saat itu. Hasil baru bisa dilihat setelah tujuh hari, yaitu pada saat orang yang diundang betul-betul menghadiri pesta pernikahan. Undangan mappitu dalam penelitian ini mencapai hasil yang diharapkan karena tamu kehormatan yang diundang secara mappitu menghadiri pesta pernikan. Mappitu memiliki unsur: Setting: bola arung 'rumah bangsawan' partisipan tujuh orang berpakaian adat dan seorang tuan rumah, ends: mengudang, act: 
mappacci, akad nikah, dan maparola, key: formal, norma: sipakatau, dan genre: mappitu

Berdasarkan kesimpulan dari hasil penelitian di atas. Saran untuk penelitian ini sebagai berikut:

1. Pemangku Adat

Pemangku adat, tokoh masyarakat seyogyanya menjadi pioner dalam melestarikan budaya Mappitu dalam masyarakat Bugis.

2. Guru Bahasa Indonesia

Hasil penelitian ini dapat dikemas menjadi materi pelajaran bahasa Indonesia. Tatacara berbahasa yang santun berdasarkan konteks. Pengembangan kosa kata dan pelestarian budaya dengan menyesuaikan pada KD Kurikulum 2013 yang ada dalam pelajaran bahasa Indonesia

\section{DAFTAR PUSTAKA}

Afful, Isaac.(2017)." An Ethnography of Communication: Viva Voce in a Ghanaian University." International Journal of Language and Linguistics. 5(5), 127-134.

Azis dan Juanda. (2017). "Kohesi Gramatikal: Kajian Keutuhan Wacana Tugas Mahasiswa Pendidikan Bahasa Dan Sastra Indonesia, Fakultas Bahasa Dan Sastra, Universitas Negeri Makassar.'BAHASA DAN SENI, 45(2), 170-180.

Azis dan Juanda. (2018). "Deixis of Narration: Research at the Student Education Indonesian Language an Literature, Faculty of Language and Literature, State University of Makassar." ISLLE 2017 the 1st Internatioanl Seminar on Language, Literature and Education, Vol. 2018, 212-217

Balboni, Paolo E. and Fabio Caon. (2014). "A Performance-oriented Model of Intercultural Communicative Competence." http://www.immi.se/intercultural/nr35/balbon i.html,

Dowlatabadi , Hamidreza and Leyli Jorfi.(2015). “A Sociocultural Perspective on Everyday Interactions Stressing Grammatical vs. Communicative Competence: The Case of Iranian Taxi-discussions." Theory and Practice in Language Studies, 5( 8), 16521658.

Garde, Murray. (2013). Culture Interaction an Person Reference in an Australian Language, vol. 11. Amsterdam: John Benyamin Publishing Company.

Halliday, M.A.K.(1984). Language as Social Semiotic, Victoria: Edward Arnold.

Hymes, Hymes. (1972). "Toward Ethnographies of Communication: The Analysis of
Communicative Events." In P. Giglioli (ed.), Language and Social Contex. 2143.Harmondsworth: Penguin,

Hymes,D.(1974).Foundation in Sociolinguistics An Ethnographic Philadelphia:Pensylvania Press.

Juanda,Juanda.(2010).’Peranan Pendidikan Formal dalam Proses Pembudayaan." Lentera Pendidikan, Jurnal Ilmu Tarbiyah dan Keguruan,13(1),1-15.

Juanda, Juanda. (2011). Analisis Wacana. Makassar: Badan Penerbit Universitas Negeri Makassar.

Kundharu, Saddhono. (2013). "The Language Usage in The Discourse of Friday Preaching." KARSA, 21( 2), 237-254.

Madyananda, Ulinnuha dan Umi Yaryati. (2017). "Nilai Pendidikan Novel Padang Bulan serta Pemanfaatannya dalam Pembelajaran Bahasa Indonesia di SMP." Jurnal Pendidikan Bahasa Dan Sastra Indonesia, 2(2), 63-68.

Nevins, M.Eleanor. 2013. "Grow with That, Walk with That": Hymes, Dialogicality, and Text Collections." Journal of Folklore Research, 50, (1), 79-116. Published by Indiana University Press.

Pasalo, Alessadra. 2015." The Value of Conversation Analysis for the Study of Children's Mental Health," in The Palgrave Hanbook of Child Mental Health: Discourse and Conversation Studies, Michelle and Jessica Nina Lester (eds.). US: Palgrave Macmillan.

Renkema, Jan.Discourse Studies, An Introductory Textbook, Amsterdam: John Benyamins Publishing Company, 1993.

Reyaz, Aiman dan Priyanka Tripathi . 2016. ”How Cultures Talk: A Study of Dell Hymes' Ethnography of Communication." Journal of Humanities and Cultural Studies R\&D. 1-10.

Sandel,Tod L.. 2015. Dialects. The International Encyplopedia of Language and Social Interaction, Karen T. Cornelia I, Todd S. (Eds.).John Walet Sons Published.

Schiffrim, Deborah.Approaches to Discourse, Massachusetts: Blackwell, 1994.

Smith, Daniel Lynwood. 2012. The Rhetoric of Interruption: Speech-Making, Turn-Taking, and Rule Breaking in Luke-Acts and Ancient Greek Narrative. Boston: De Gruyter

Wiratno, Tri. 2010. "Analisis Percakapan Terhadap Drama Kapai-Kapai Karya Arifin C. Noer.” Kajian Linguistik dan Sastra, 22(1), 117132.

Yang, Wei Dong. 2007. " Realization of TurnTaking in Conversation Interaction." USForeign Language, 5(8), 19-30. 